\title{
ESTUDO DA VARIAÇÃO DO LIMITE DE RESISTÊNCIA À TRAÇÃO AO LONGO DA BOBINA DE VERGALHÃO DE ALUMÍNIO 1350 AA* $^{*}$
}

Renan Tavares Ruy ${ }^{1}$

\section{Resumo}

Esse trabalho tem como objetivo buscar um melhor entendimento dos fatores que influenciam de forma significativa nas propriedades mecânicas do vergalhão 1350AA, avaliando especificamente a influência da temperatura de bobinamento. Foram retiradas amostras de seis bobinas e então submetidas à diferentes temperaturas de recozimento por um período específico e analisadas mecanicamente e microscopicamente. Os ensaios de tração mostraram que o alumínio 1350 AA sofre uma influência significativa da temperatura, cujo comportamento foi muito similar ao apresentado na literatura. Constatou-se que o fenômeno de recuperação ocorreu de forma mais significativa a temperaturas elevadas. O trabalho permitiu concluir que é necessário um resfriamento mais eficiente no vergalhão para que a variação de LRT seja minimizada.

Palavras-chave: Vergalhão de alumínio 1350 AA; Recozimento; Recuperação; Limite de resistência a tração.

\section{STUDY OF THE VARIATION OF THE LIMIT TENSILE STRENGTH IN A BOBINE OF ALUMINUM 1350 AA}

\section{Abstract}

This work aims to seek a better understanding of the factors that significantly influence the mechanical properties of rebar 1350AA, specifically assessing the influence of coiling temperature. The samples were taken from six coils and then subjected to different annealing temperatures for a specific period and analyzed microscopically and mechanically. Tensile tests showed that the AA 1350 aluminum undergoes a significant influence of temperature, whose behavior was very similar to that presented in the literature. It was found that the recovery phenomenon occurred more significantly at elevated temperatures. The study concluded that a more efficient cooling is required in rebar to reduce the variation of LRT.

Keywords: Aluminum 1350 AA rebar; Annealing; Recovery; Limit of tensile strength. 


\section{INTRODUÇÃO}

Esse trabalho foi desenvolvido visando compreender melhor os fatores responsáveis por provocar uma variação significativa do LRT ao longo da bobina de vergalhão 1350 AA, buscando através desse estudo, uma solução para esse problema.

\subsection{Recristalização e Recuperação}

Um dos fatores que mais afetam microestruturalmente um metal deformado é a energia de defeito de empilhamento (EDE), que influencia fortemente a distribuição das discordâncias. Para um metal deformado, cuja energia de falha de empilhamento é baixa, a mobilidade das discordâncias também é baixa, pois encontram-se muito afastadas umas das outras, dificultando a ocorrência de fenômenos como o escorregamento com desvio ("cross-slip") e escalada ("climb") de discordâncias, favorecendo uma distribuição planar (homogênea) na microestrutura, conforme mostrado na Figura 1 [1].

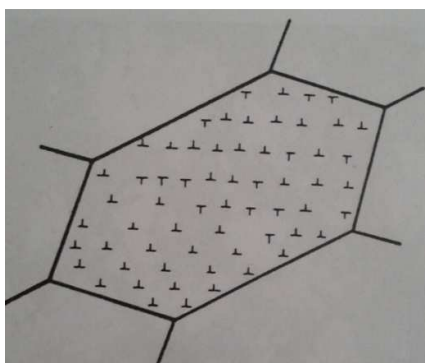

Figura 1. Arranjo planar de discordâncias homogeneamente distribuídas em grão encruado.

O contrário é verificado quando o metal possui elevada energia de defeito de empilhamento, uma vez as discordâncias possuem alta mobilidade. Nessa condição, a distribuição tende a ser heterogênea, concentrando-se nos contornos e interiores de grãos encruados, conforme mostrado na Figura 2.

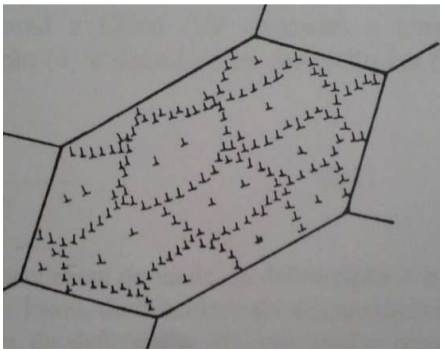

Figura 2. Arranjo celular esquemático de discordâncias em grão encruado.

Observa-se também que discordâncias vizinhas e de sinais opostos podem aniquilar-se [1].

As alterações microestruturais que ocorrem durante a recuperação levam a uma restauração parcial das propriedades do material, tais como mecânicas, de resistividade elétrica, além da densidade e tensões residuais iniciais.

$\mathrm{O}$ alumínio possui uma temperatura de fusão absoluta de $660^{\circ} \mathrm{C}$. Em temperaturas superiores a $0,2 \mathrm{Tf}\left(132^{\circ} \mathrm{C}\right)$ observa-se principalmente a ocorrência de aniquilação de intersticiais e lacunas e a migração de defeitos puntiformes para os contornos de grãos e discordâncias. Temperaturas entre 0,2 e 0,3 Tf (132 a 198으) observa-se a aniquilação de discordâncias de sinais opostos e estas se rearranjam, delineando-se 
os contornos de baixo ângulo (subcontornos de grãos), no entanto a formação desses subcontornos requer uma maior energia de ativação (térmica), devido à necessidade de ocorrência dos fenômenos de escorregamento com desvio e escalada, geralmente observados em temperaturas maiores que $0,4 \operatorname{Tf}\left(264^{\circ} \mathrm{C}\right)$. No caso do alumínio, que possui elevada EDE, o papel da recuperação torna-se ainda mais importante, pois esse rearranjo microestrutural promove uma diminuição considerável da energia interna, que está associada a esses defeitos, levando também a uma redução das propriedades mecânicas no material [1].

\subsection{Influência do Recozimento na Dureza e Resistividade do Alumínio Puro}

A estabilidade térmica dos materiais severamente deformados plasticamente é geralmente baixa, apesar de suas propriedades mecânicas serem melhoradas devido à alta densidade de discordâncias.

No trabalho de $\mathrm{Zi}$ et al. [2], as energias de ativação para a recuperação e recristalização foram calculadas a partir da resposta de microdureza para recozimento isotérmico e foram encontrados, alguns processos relevantes, como o movimento de discordâncias termicamente ativadas, autodifusão, que ajudam a explicar e a descrever os processos de recristalização e de recozimento isócrono.

Experimentalmente, foi utilizado alumínio de elevado grau de pureza $(99,99 \%)$, tratado termicamente a $403 \mathrm{~K}$ durante 30 minutos. Antes da deformação o material exibiu uma microestrutura equiaxial de grãos com uma dimensão média de $113 \mu \mathrm{m}$.

$\mathrm{Zi}$, A. et al., obtiveram como resultados uma diminuição na dureza, que ocorre (a uma faixa de temperatura relativamente baixa) entre 403 e $603 \mathrm{~K}$ no alumínio deformado no processo de conformação plástica à temperatura ambiente, conforme mostrado na Figura 3. Isto ocorre devido a um elevado nível de energia que está sendo armazenado após deformação plástica, que representa a força motriz para os fenômenos de recozimento. A diminuição da dureza e da resistividade elétrica anteriores à recristalização e posterior ao recozimento para temperaturas inferiores à 523K devem ser atribuídos aos processos de recuperação.

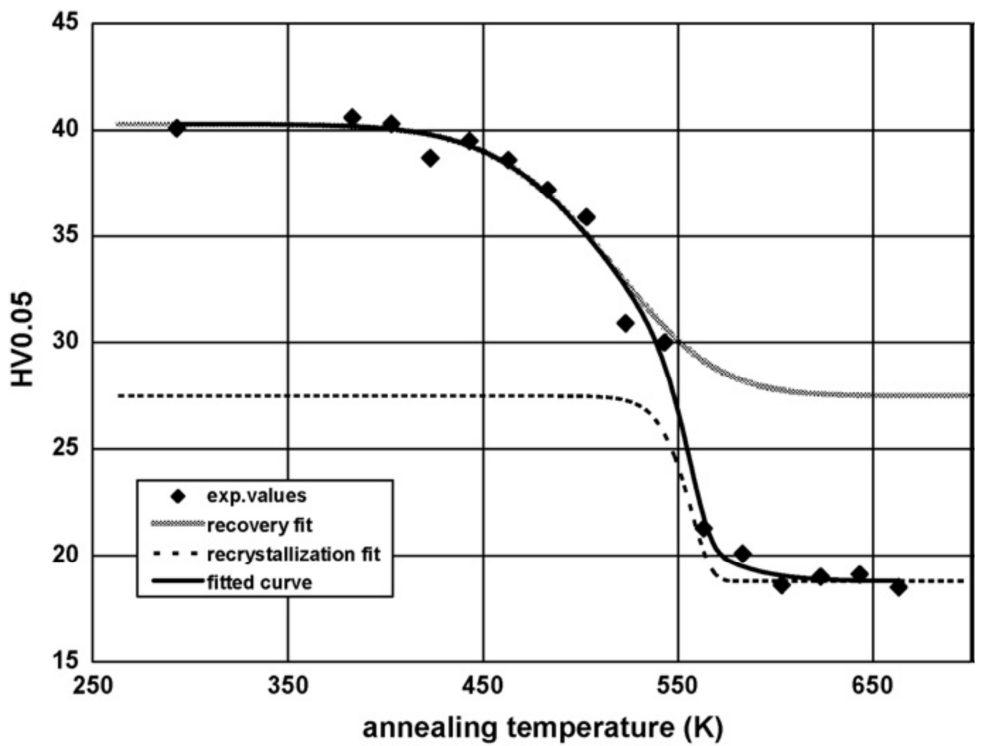

Figura 3. Microdureza Vickers em função do tratamento de recozimento isócrono no alumínio.

No estudo de Zhou et al., avaliou-se a liga 1050 AA (Al 99,5\%), considerando a influência das temperaturas de recozimento na microestrutura do material [3]. 
Após serem homogeneizados, os corpos-de-prova foram laminados à $0,5-0,8 \mathrm{~mm}$ de espessura com um grau de deformação de 2,5 e foram posteriormente recozidos às seguintes temperaturas $200,250,300,350,400$ e $450^{\circ} \mathrm{C}$ por 1 hora. As características mecânicas após esse tratamento são mostradas na Figura 4 [3].

Entre 200 e $300^{\circ} \mathrm{C}$, nota-se uma grande variação na resistência à tração, tensão de escoamento, alongamento, módulo de elasticidade e dureza (r1) [3].
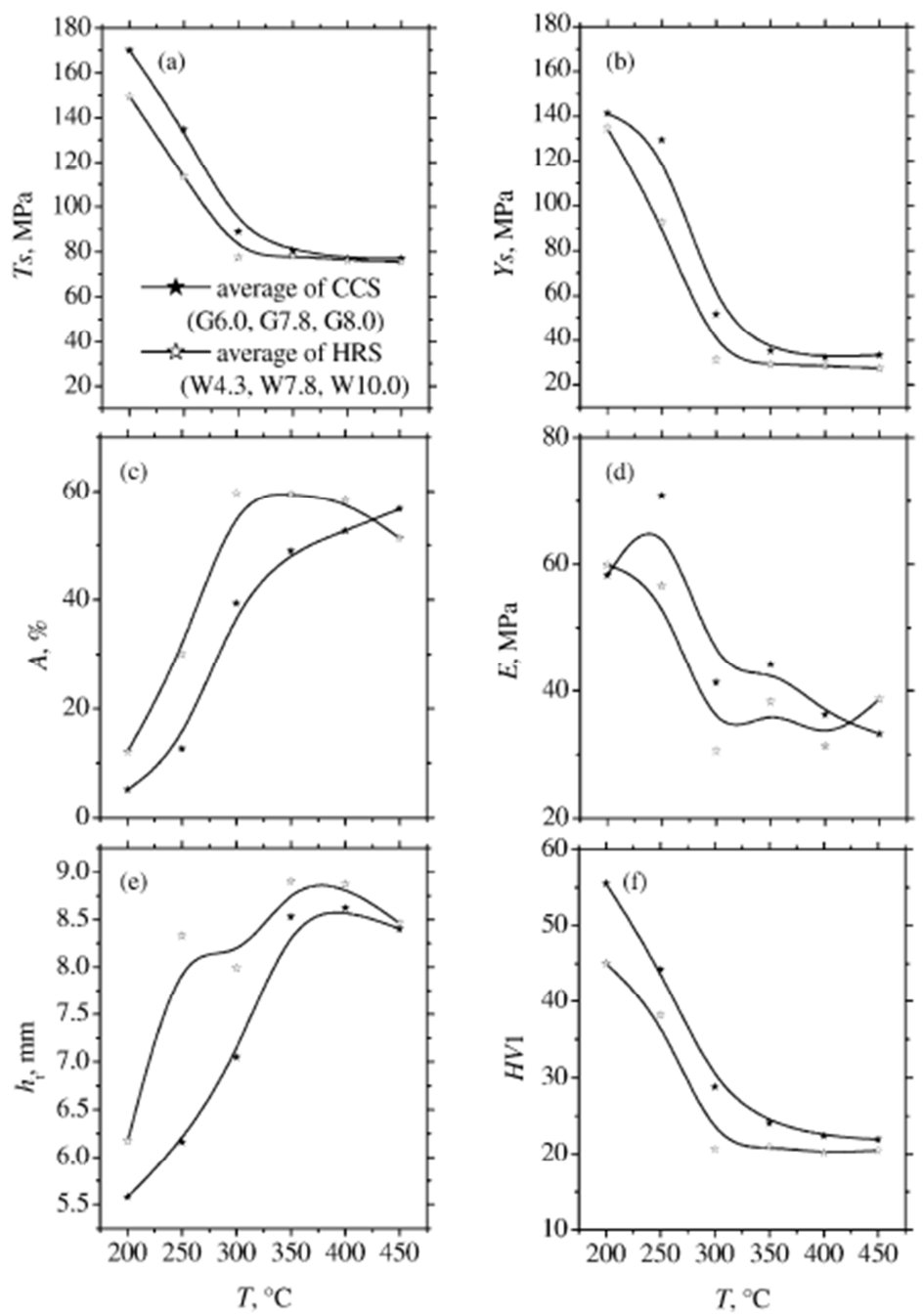

Figura 4. Influência das temperaturas de recozimento nas características mecânicas da barra.

À $200^{\circ} \mathrm{C}$ é possível observar grãos alongados devido à direção de laminação, já à $350^{\circ} \mathrm{C}$, os contornos entre os grãos recristalizados não são muito claros e à $450^{\circ} \mathrm{C}$ observa-se claramente os grãos individuais [3]. 


\section{MATERIAIS E MÉTODOS}

Preparação do produção de 6 bobinas de vergalhão 1350AA
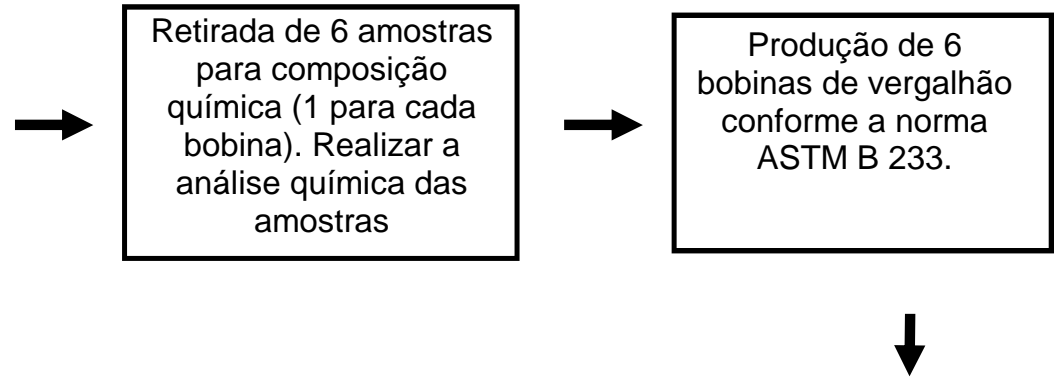

Ensaio de Tração em todas as amostras tratadas termicamente (Norma ASTM B 557)

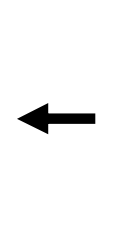
Tratamento térmico
das amostras em 9 faixas diferentes de temperaturas ( 4 amostras de cada bobina para cada faixa)
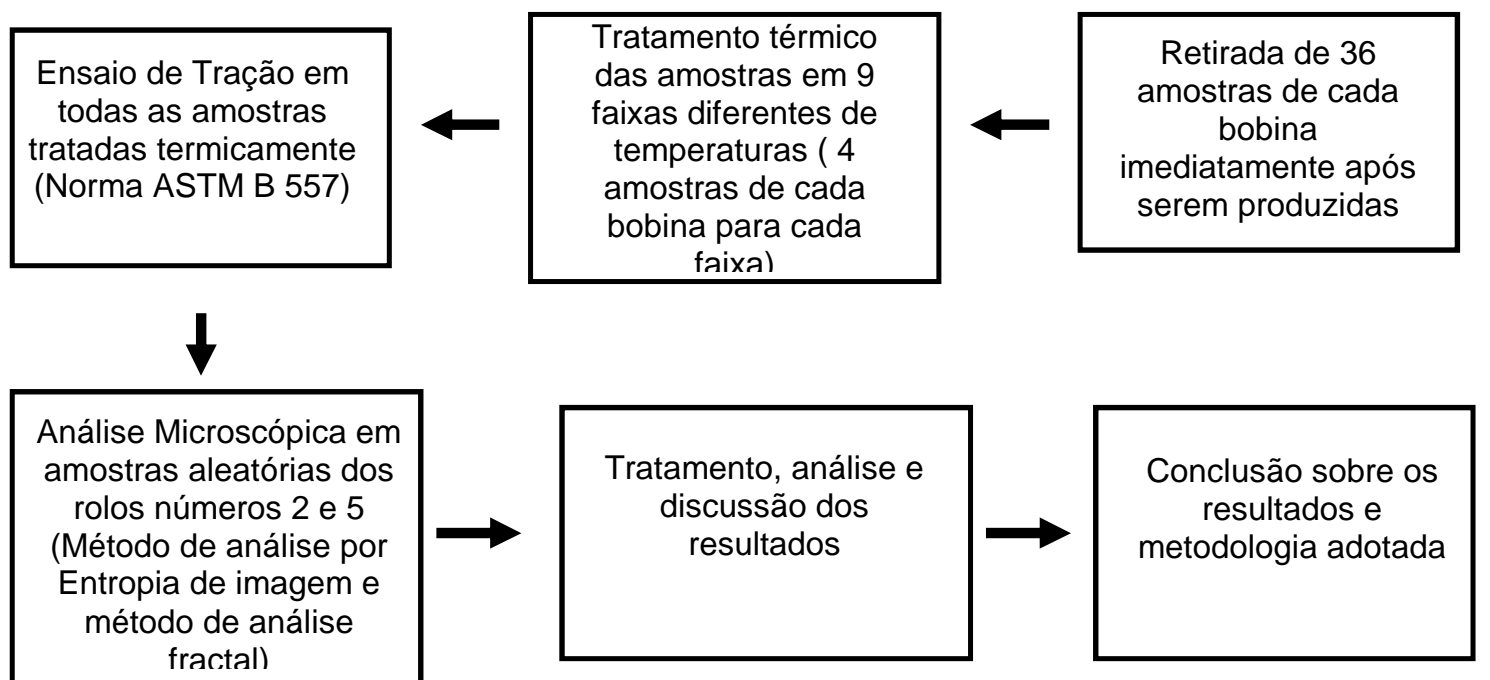

Figura 5. Fluxograma metodológico geral aplicado ao trabalho.

\subsection{Análise Química}

As etapas de tratamento térmico foram realizadas conforme a Figura 6, simulando desde as temperaturas de saída das bobinas no equipamento, representadas na Figura 7, até as temperaturas atingidas durante o resfriamento natural das bobinas.

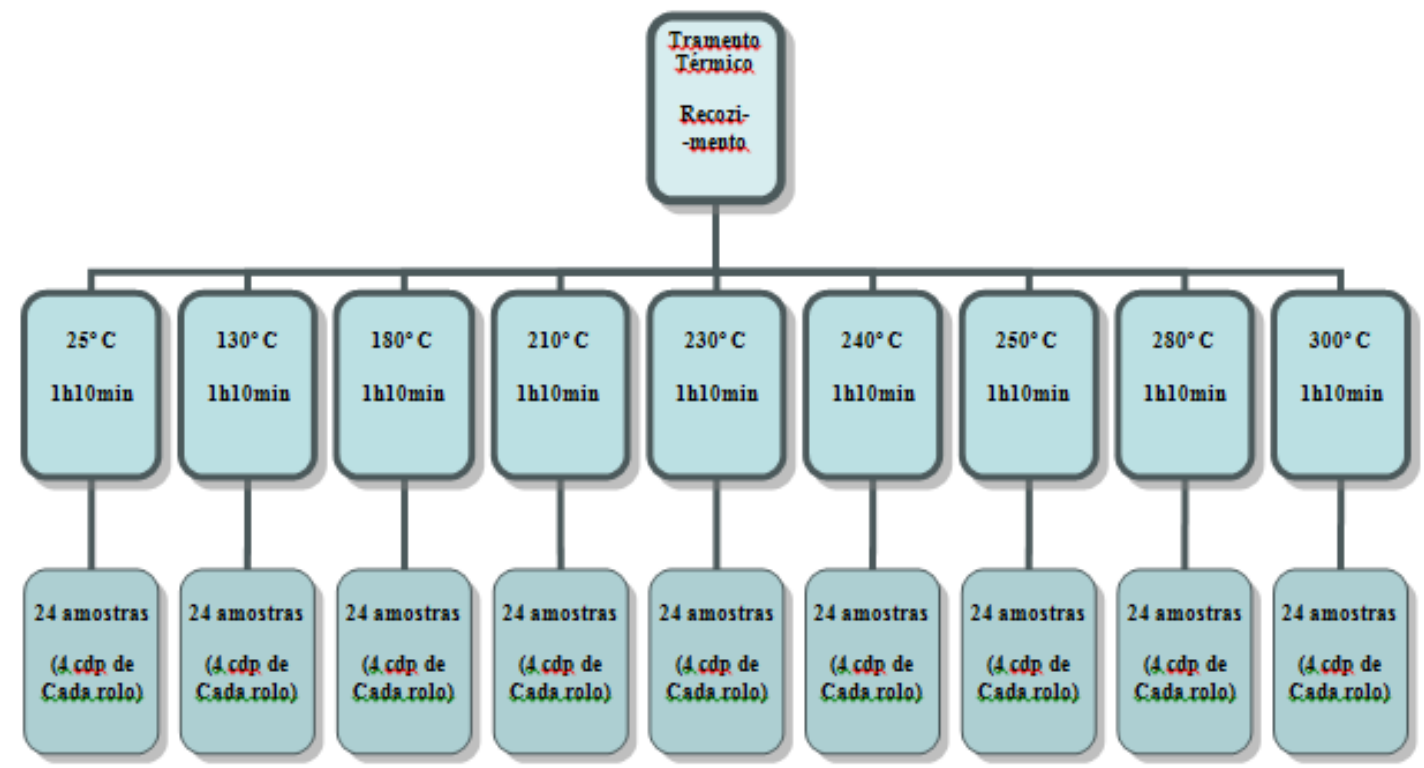

Figura 6. Esquema representativo da metodologia adotada para 0 tratamento térmico de recozimento. 


$$
>=260^{\circ} \mathrm{C}
$$

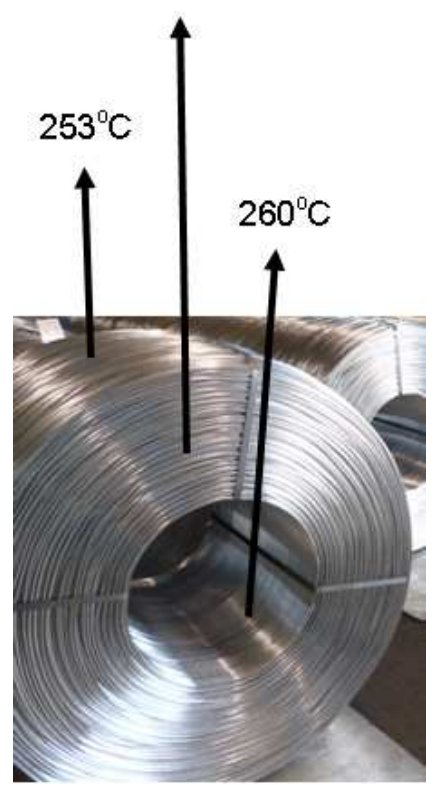

Figura 7. Gradiente de temperatura em diferentes regiões da bobina, imediatamente após ser produzida.

\section{RESULTADOS E DISCUSSÃO}

\subsection{Composição Química}

$\mathrm{Na}$ Tabela 1 estão discriminados os resultados das seis amostras, correspondentes as seis bobinas, demonstrando que a composição química das 6 bobinas estão muito próximas e atendem a norma ASTM B 233.

Tabela 1 - Composição química da liga 1350 AA durante a produção dos 6 rolos

\begin{tabular}{ccccccccccccccc}
\hline \multicolumn{10}{c}{ Composição química da liga 1350 $\mathrm{AA}$ durante a produção dos 6 rolos } \\
\hline 1 rolo & 0,057 & 0,168 & 0,017 & 0,001 & 0,002 & 0,001 & 0,003 & 0,008 & 0,003 & 0,0001 & 0,013 & 0,007 \\
2 rolo & 0,055 & 0,168 & 0,016 & 0,001 & 0,001 & 0,001 & 0,004 & 0,008 & 0,005 & $1 \mathrm{E}-04$ & 0,013 & 0,007 \\
3 rolo & 0,055 & 0,163 & 0,016 & 0,001 & 0,001 & 0,001 & 0,003 & 0,007 & 0,003 & $2 \mathrm{E}-04$ & 0,013 & 0,007 \\
4 rolo & 0,056 & 0,168 & 0,016 & 0,001 & 0,001 & 0,001 & 0,003 & 0,007 & 0,003 & 0 & 0,012 & 0,007 \\
5 rolo & 0,057 & 0,168 & 0,016 & 0,001 & 0,001 & 0,001 & 0,003 & 0,008 & 0,004 & $1 \mathrm{E}-04$ & 0,013 & 0,007 \\
6 rolo & 0,056 & 0,168 & 0,016 & 0,001 & 0,001 & 0,001 & 0,003 & 0,008 & 0,003 & 0 & 0,013 & 0,007 \\
Média & 0,056 & 0,167 & 0,0162 & 0,001 & 0,001 & 0,001 & 0,003 & 0,008 & 0,004 & $0 \mathrm{E}+00$ & 0,013 & 0,007 \\
Desvio pad & 0,001 & 0,002 & 0,000 & 0 & 0,0004 & 0 & $4 \mathrm{E}-04$ & 0,001 & $8 \mathrm{E}-04$ & $8 \mathrm{E}-05$ & 0,0004 & $9 \mathrm{E}-05$
\end{tabular}

\subsection{Ensaio de Tração}

No gráfico da Figura 8 estão representados os valores de LRT obtidos nos ensaios de tração para todas as amostras em função das temperaturas de recozimento e na Figura 9, os valores médios de LRT foram plotados no Gráfico. O comportamento em tração do alumínio 1350 AA em diferentes faixas de temperatura pode ser traduzido pela Equação 1, obtida do próprio gráfico com um valor de $\mathrm{R}^{2}$ igual a 0,9817 , indicando que há uma forte correlação entre o comportamento e a equação que o descreve.

Utilizando a Equação 1, pode-se calcular o valor aproximado de LRT para as temperaturas de saída da bobina, conforme as medições realizadas. 


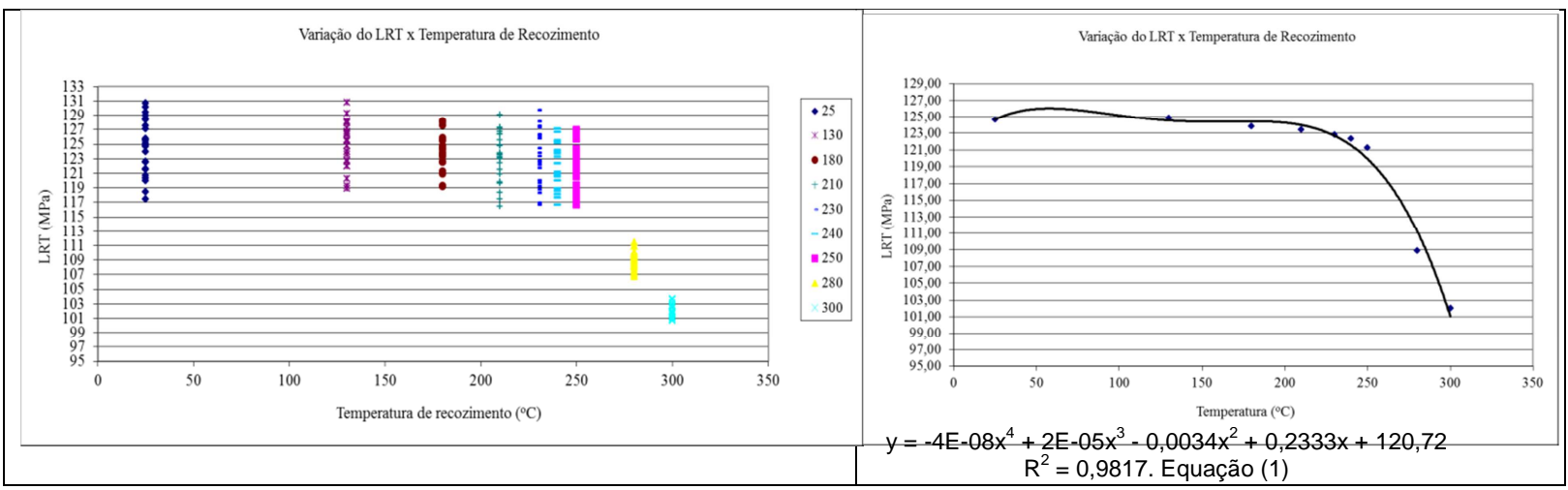

Figura 8. Gráfico da variação do LRT em função das temperaturas de recozimento.

Figura 9. Gráfico da variação do LRT médio em função das temperaturas de recozimento.

Conforme o trabalho de $\mathrm{Zi}$ et al. [2], utilizado como referência, o comportamento do alumínio 1350 AA, de elevada pureza, está associado ao fenômeno de recuperação do material. Embora tenha sido avaliada nesse trabalho a variação da microdureza em função das temperaturas de recozimento, esse mesmo comportamento pode ser adotado para o material solicitado em tração, pois são propriedades que estão relacionadas à microestrutura e quanto mais resistentes, maiores serão os valores de dureza. As elevadas temperaturas de saída das bobinas promovem um recozimento a uma temperatura cuja mobilidade das discordâncias é elevada, sobretudo no alumínio. O rearranjo das discordâncias resulta em uma diminuição do encruamento, reduzindo assim a sua resistência mecânica, análogo ao trabalho de Zhou et al. [3].

Para temperaturas menores que $210^{\circ} \mathrm{C}$ pode-se observar que não há uma variação significativa no limite de resistência a tração para a liga $1350 \mathrm{AA}$, porém a partir dessa temperatura, a diminuição da resistência mecânica começa a ser mais acentuada, sobretudo a partir de $250^{\circ}$ C que passa a ser mais brusca e esse comportamento pode ser descrito pela Equação 1.

O alumínio é um material que possui um elevado consumo de energia de falha de empilhamento, ou seja, as discordâncias têm grande mobilidade e potencializam o efeito de recuperação, de forma muito mais evidente que em outros materiais como o cobre por exemplo.

Como as curvas encontradas experimentalmente seguem a mesma tendência que as curvas teóricas, pode-se afirmar que o comportamento mecânico da liga $1350 \mathrm{AA}$ quando submetida a diferentes gradientes de temperatura de recozimento está diretamente relacionado ao fenômeno de recuperação do material.

\subsection{Análise Microscópica}

Após todo processo de preparação, foi montado um mapa de imagens cara cada condição, composto por 81 fotos cada, descrevendo assim, com uma maior riqueza de detalhes, as características microestruturais para cada corpo-de-prova produzido, obtendo-se, portanto, 18 Mapas, que foram analisados através dos métodos de análise por Entropia de Imagem e método de análise Fractal.

A Figura 10 mostra um exemplo de um dos 18 mapas analisados em condições de tratamento térmico diferentes. 


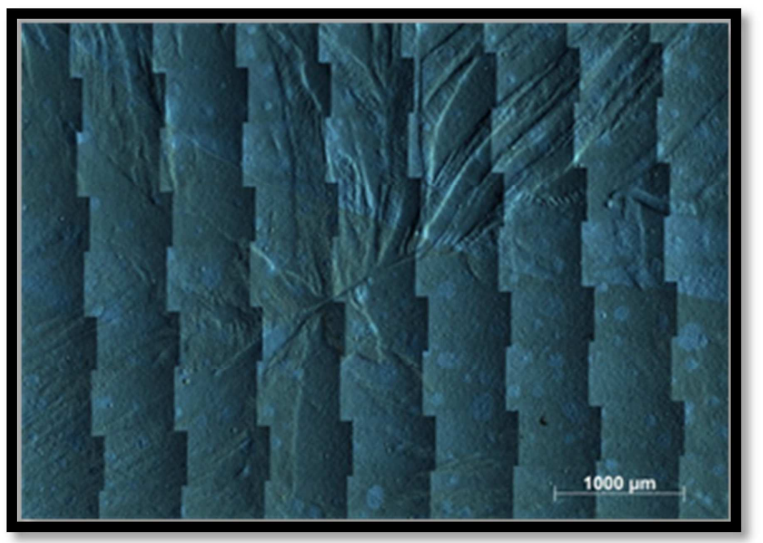

Figura 10. Mapa de 81 imagens representando a condição de recozimento a $250^{\circ} \mathrm{C}$.

\subsubsection{Análise por entropia de imagem}

O método de análise por Entropia de Imagem consiste na avaliação da textura (Fatores morfológicos com tons de cinza semelhantes), levando-se em conta uma avaliação probabilística dos tons de cinza. Neste caso, superfícies mais encruadas possuem mais bandas de deformação (regiões com sombras), refletindo em uma textura com maior quantidade de alternâncias ou seja, com uma maior Entropia.

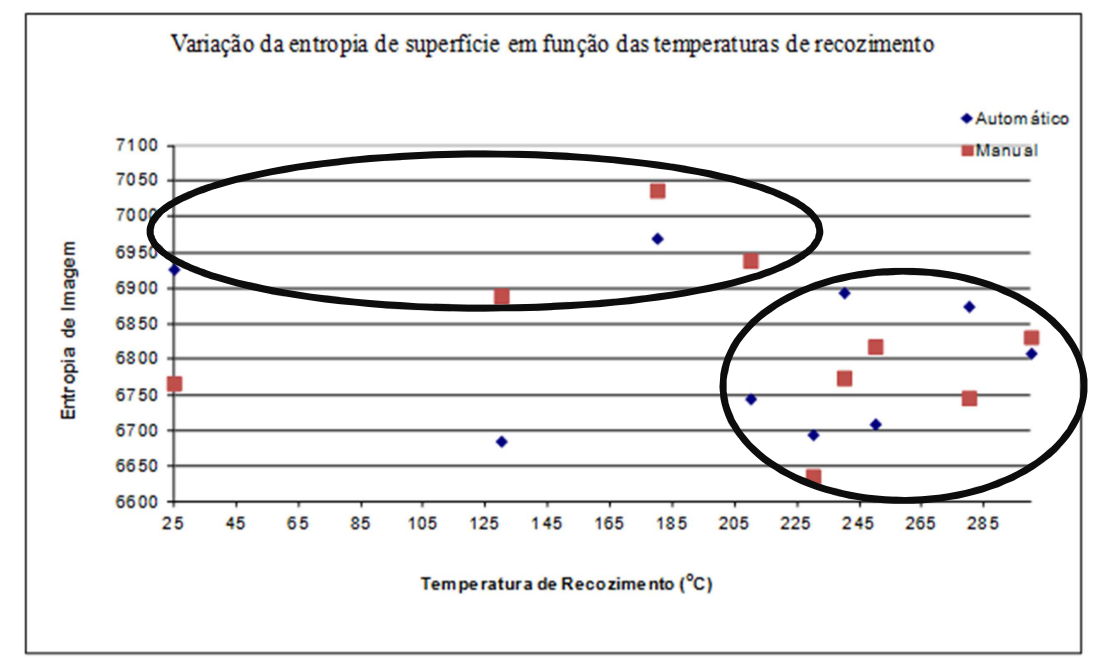

Figura 11. Variação das Entropias Médias em função das temperaturas de recozimento.

Na Figura 11 pode-se observar que os resultados, para ambos os casos, não seguem exatamente o mesmo comportamento dos resultados dos ensaios mecânicos, mas se forem considerados 2 grupos diferentes, o primeiro contendo as amostras normalizadas e recozidas até $210^{\circ} \mathrm{C}$ e o segundo as demais amostras, acima de $210^{\circ} \mathrm{C}$, pode-se observar uma tendência, onde os valores de entropia são menores no segundo grupo, conforme esperado, porém esse método de análise é muito influenciado pelas condições superficiais das amostras, como riscos, incrustações e manchas que influenciam nos resultados, o que explica o comportamento obtido. Mesmo filtrando alguns valores discrepantes, a média ainda mostrou-se influenciada pelas características irregulares da superfície.

As entropias podem ser utilizadas nas análises dos resultados, mas de forma complementar aos ensaios mecânicos, pois fornecem algumas evidências sobre o efeito da recuperação no material, porém apresentam ainda alguns desvios nos 
resultados e por isso não devem ser consideradas como a principal forma de análise do efeito da temperatura de recozimento no alumínio 1350 AA.

Realizou-se também um teste de paridade para os resultados das entropias das amostras normalizada e recozida à $250^{\circ} \mathrm{C}$, conforme mostrado na Tabela 2 , mostrando que as médias são diferentes e que a análise por meio das entropias é capaz de diferenciar amostras mais encruadas de amostras mais lisas, associandoas ao comportamento de recuperação do material, mesmo não sendo um resultado muito preciso.

Tabela 2 - Teste de Paridade para Entropias de Imagens a $25^{\circ} \mathrm{C}$ e a $250^{\circ} \mathrm{C}$

\begin{tabular}{rrrr} 
Teste: 2 sample t & $25^{\circ} \mathrm{C}$ & $250^{\circ} \mathrm{C}$ & $\mathrm{p}<0,05$ \\
\hline Modo Automático & Entropia & Entropia & Valor $\mathrm{p}$ \\
\hline & 6927,00 & 6710,00 & 0,000
\end{tabular}

\subsubsection{Análise de dimensão fractal}

O método de análise por Dimensão Fractal consiste na medida de rugosidade através dos tons de cinza. Neste caso, superfícies mais encruadas possuem mais bandas de deformação, refletindo em uma maior rugosidade, representando uma maior dimensão fractal.

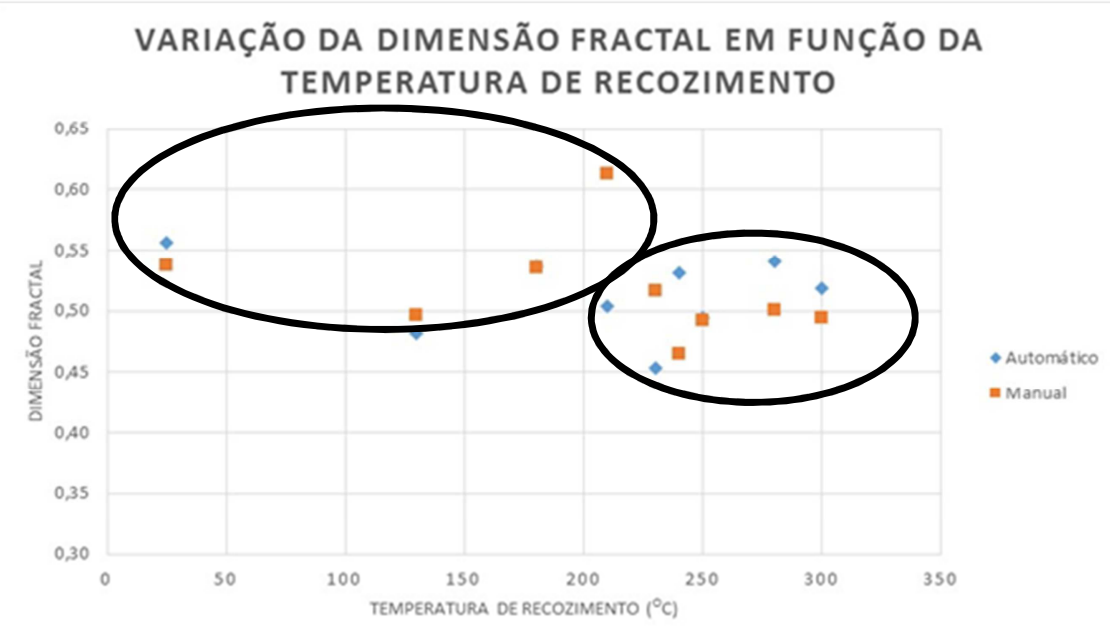

Figura 12. Variação das dimensões fractais em função das temperaturas de recozimento.

A Figura 12 mostra um comportamento dos resultados das dimensões fractais semelhante ao dos resultados das entropias de imagem, mostrando que ambos os métodos, mesmo sendo influenciados de formas distintas pela qualidade da superfície, produzem resultados muito semelhantes, fortalecendo ainda mais a hipótese de que as mudanças de rugosidade na superfície dos corpos-de-prova podem ser associadas ao efeito da recuperação devido a temperatura de recozimento.

Regiões mais deformadas possuem uma maior densidade de discordâncias, logo, a energia de ativação para ocorrer a recuperação no material será menor. Como os tempos de recozimento foram os mesmos, espera-se que a recuperação ocorra mais rapidamente em amostras mais encruadas. Esse fato é corroborado pelos resultados dos ensaios mecânicos. 


\section{CONCLUSÃO}

Este trabalho permitiu concluir que o vergalhão 1350 AA sofre recuperação em função da temperatura de recozimento e que este fato está diretemente relacionado com a temperatura de bobinamento.

Através das análises das variações dos limites de resistência a tração em função das temperaturas de recozimento pôde-se concluir que, acima de $210^{\circ} \mathrm{C}$, a recuperação influencia mais sobre o LRT e que entre $250^{\circ} \mathrm{C}$ e $300^{\circ} \mathrm{C}$, há uma queda brusca no LRT.

Pôde-se também concluir que os métodos de análise das imagens por meio das entropias superficiais e das dimensões fractais mostraram-se capazes de diferenciar amostras encruadas de amostras mais lisas e possivelmente recuperadas, sobretudo ao se realizar um teste de paridade entre as amostras de um mesmo rolo, sendo uma normalizada e outra recozida à $250^{\circ} \mathrm{C}$, mostrando que as médias eram diferentes. Isso demonstra que esse método é de certa forma robusto em determinadas condições, quando associados à análises mecânicas, por exemplo, pois apresentam algumas inconsistências quanto aos resultados, uma vez que são muito influenciados pelas condições de acabamento superficial das amostras.

Por fim, pode-se concluir que o efeito da recuperação no alumínio 1350 AA pode ser minimizado através de uma refrigeração eficiente no vergalhão antes do seu bobinamento, garantindo que o rolo saia da máquina a uma temperatura de no máximo $210^{\circ} \mathrm{C}$. O recozimento é apenas um dos fatores que influenciam na variação do LRT, porém é possível afirmar que o controle desse parâmetro é de suma importância para a diminuição da variação nas propriedades mecânicas do material.

\section{REFERÊNCIAS}

1 PADILHA, A. F.; JR, F. S. Encruamento, recristalização, crescimento de grão e textura. 2.ed. São Paulo: ABM, 1996. v 1, 158p.

2 ZI, A.; STULIKOVA, I.; SMOLA, B. Response of aluminum processed by extrusion proceded ECAP to isochronal annealing. Materials Science and Engineering A, [s.I.], v. 527, p. 1469-1472, oct. 2009.

3 ZHOU, S. X. et al. Experimental study on materials properties of hot rolled and continuously cast aluminum strips in cold rolling. Journal of Materials Processing Technology, [s.I.], v. 134, p. 363-373, nov. 2002. 